\title{
Are the UK oncology trainees adequately informed about the needs of older people with cancer?
}

\author{
T Kalsi $^{*, 1,2}$, S Payne $^{3}, \mathrm{H} \mathrm{Brodie}^{4}, \mathrm{~J} \mathrm{Mansi}^{5,6}, \mathrm{Y} \mathrm{Wang}^{2}$ and D Harari ${ }^{1,2}$ \\ ${ }^{1}$ POPS-GOLD, Older Person's Assessment Unit, Department of Ageing of Health, Guys Hospital, Guys and St Thomas' NHS \\ Foundation Trust, Ground Floor Bermondsey Wing, Great Maze Pond, London SE1 9RT, UK; ${ }^{2}$ Division of Health and Social Care \\ Research, King's College London, Capital House, 42 Weston Street, London SE1 3QD, UK; ${ }^{3}$ Department of Medical Oncology, \\ St Bartholomew's Hospital, Smithfield West, London EC1A 7BE, UK; ${ }^{4}$ Macmillan Cancer Support, 89 Albert Embankment, London \\ SE1 7UQ, UK; ${ }^{5}$ Department of Medical Oncology, Guys Hospital, Guys and St Thomas' NHS Foundation Trust, Great Maze Pond, \\ London SE1 9RT, UK and ' NIHR Biomedical Research Centre, Kings College London, Guys Hospital, 16th Floor, Tower Wing, \\ Great Maze Pond, London SE1 9RT, UK
}

Background: Outcomes for older people with cancer are poorer in the United Kingdom compared with that in other countries. Despite this, the UK oncology curricula do not have dedicated geriatric oncology learning objectives. This cross-sectional study of UK medical oncology trainees investigates the training, confidence level and attitudes towards treating older people with cancer.

Methods: A web-based survey link was sent to the delegates of a national medical oncology trainee meeting. Responses were collected in October 2011.

Results: The response rate was $93 \%$ (64 out of 69). The mean age of the respondents was 32.3 years (range $27-42$ years) and $64.1 \%$ were female. A total of $66.1 \%$ of the respondents reported never receiving training on the particular needs of older people with cancer, $19.4 \%$ reported to have received this training only once. Only $27.1 \%$ of the trainees were confident in assessing risk to make treatment recommendations for older patients compared with $81.4 \%$ being confident to treat younger patients. Even fewer were confident with older patients with dementia (10.2\%).

Conclusion: This first study of the UK medical oncology trainees highlights the urgent need for change in curricula to address the complex needs of older people with cancer.

Outcomes for older people with cancer are poorer in the United Kingdom compared with that in other countries (Coleman et al, 2011). Managing this patient group can pose a significant challenge. Older people with cancer are a heterogeneous group; they commonly have different comorbidities of varying severities, agerelated changes in physiological function, and social and functional issues that may be complex. These multiple factors can make cancertreatment decisions difficult. To adequately manage this group, specialist training needs to incorporate learning objectives related to the specific needs of older people with cancer. This is both to enable well-informed decision-making and to identify unmet needs to provide the necessary support before and during cancer treatment.

Postgraduate oncology training differs across the world, but some developed countries have begun to recognise the need for change in curricula to include the subspecialty of geriatric oncology. The United States have made particular progress. They recognised the importance of integrating geriatrics training in oncology in the 1990s (Kennedy, 1997) and identifed training priorities (Cohen, 1997). In 2005, the core curriculum produced by the Association of Clinical Oncology (ASCO) included a dedicated section on geriatric oncology (Muss et al, 2005). The curriculum

*Correspondence: Dr T Kalsi; E-mail: tania.kalsi@gstt.nhs.uk

Received 2 January 2013; revised 14 March 2013; accepted 1 April 2013; published online 30 April 2013

(c) 2013 Cancer Research UK. All rights reserved 0007-0920/13 
introduced trainees to the biology of cancer in ageing, physiological changes in ageing and the psychosocial aspects of cancer in older people. It also directed trainees to the unique aspects of assessing older people with the evidence-based 'comprehensive geriatric assessment' (CGA; Stuck et al, 1993). In 2010, ASCO with their European colleagues (European Society of Medical Oncology (ESMO)) further developed and created a global curriculum. This guided trainees to similar learning objectives and towards competency in specific geriatric syndromes, such as falls, incontinence, delirium and depression. The progress in the United States was noted in a survey of training programme directors in 2008, where $32 \%$ reported formal and $56 \%$ informal coverage of geriatric oncology in their curriculum (Naeim et al, 2010). The impact of curriculum change on patient outcomes has not been reported.

There are few joint fellowships in geriatrics and oncology worldwide. The need for these joint fellowship programmes was identified in the United States in the 1990s (Bennett et al, 1997; Lichtman 2000). These programmes later became available in selected medical centres (Bennett et al, 2010). In Europe, opportunities appear to exist only in France (Terret et al, 2004) and Italy (Khattak, 2011).

International bodies, including the International Society of Geriatric Oncology (SIOG), have supported curricula change. SIOG is an international multidisciplinary society of oncologists, geriatricians and allied health professionals. The strategic direction of SIOG regarding education includes geriatric oncology integration into the curricula.

In the United Kingdom, oncologists train as 'clinical' or 'medical' oncologists. Medical oncologists are physicians who specialise in the management and treatment of patients with cancer and, in particular, in the administration of systemic therapies, whereas clinical oncologists additionally train in the delivery of radiotherapy. Neither the current medical nor the clinical oncology curriculum have dedicated learning objectives related to geriatric oncology. However, both curricula include specific learning objectives related to the management of adolescents. There are no joint geriatrics and oncology fellowship programmes available in the United Kingdom.

There has been very little research in identifying the geriatric oncology training needs of oncology trainees across the globe, and we found no research on this in the United Kingdom. There is an urgent need to identify current training gaps in the United Kingdom, to enable curricula development to address the needs of older people with cancer.

The purpose of this survey of the UK medical oncology trainees was to investigate the training, confidence and attitudes towards treating older people with cancer. Current practice around cognitive impairment was particularly explored. Cognitive impairment and dementia is becoming increasingly common (Ferri et al, 2005). It can be a particular challenge when making cancertreatment decisions and in consenting (Extermann, 2005), and patients with dementia have been observed to receive less intense cancer treatment (Gupta and Lamont, 2004). In addition, in the United Kingdom, laws to protect those without capacity to consent were passed in 2005 with the Mental Capacity Act (MCA). It is expected in the United Kingdom that all health workers should be familiar with this law and should be able to assess mental capacity (Nicholson et al, 2008).

\section{MATERIALS AND METHODS}

Setting, participants and recruitment. The survey targeted medical oncology trainees using a web-based survey link (Survey Monkey). The link was sent via e-mail to the 69 delegates of a national medical oncology trainee meeting. Responses were collected in October 2011.
Questionnaire design. The questionnaire is available online in the Supplementary Material).

The questionnaire consisted of three sections:

1. Characteristics of respondents.

2. Training exposure to geriatric medicine and geriatric oncology. This included exploring the training the trainees felt they needed, so as to identify any unpredicted training needs.

3. Confidence, current practice and attitudes towards treating older people. This included the trainee's confidence in managing older people in specific scenarios, the perceived barriers to chemotherapy in older people, and the practice and attitudes towards managing those with cognitive impairment/ dementia.

Most questions were asked using a five-point Likert scale. Questions were reviewed by three clinicians and one non-clinician for readability before dissemination. The overall content validity ratio (Lawshe, 1975) was 0.80 .

The three questions (with subquestions) around training exposure were designed to identify the amount of general geriatrics training received during undergraduate and postgraduate training, and then, more specifically, to the geriatric oncology training in their specialty training programmes. Training around specific geriatric oncology relevant topics (falls, delirium, MCA, polypharmacy, nutrition and continence) were chosen to reflect the objectives in the ASCO/ESMO global curriculum. These issues are common in older people (Lawlor et al, 2000; Allan-Gibbs, 2010 and are associated with significant morbidity and mortality. They may be exacerbated or precipitated by particular cancer treatments, such as urinary incontinence in prostate cancer treatments (Bates et al, 1998) or falls with chemotherapy-induced peripheral neuropathy (Tofthagen et al, 2012). Training wishes were asked as a free text response to explore whether there were unpredicted training needs.

Trainee confidence in managing older adults in specific clinical scenarios was explored in a five-part question. This included confidence in assessing risk to make cancer treatment recommendations in patients over 70 years and in a patients in their 40s. Confidence in making cancer treatment recommendations in the context of dementia and in patients with multiple comorbidities (such as ischaemic heart disease or diabetes), and the confidence in managing these comorbidities were also explored. Beliefs around which circumstances chemotherapy should be offered and the perceived barriers were identified in two multiple-part questions.

Oncology practice and confidence in making treatment recommendations in the context of cognitive impairment was explored. We asked how cognition was assessed and whether validated cognitive screening tools were used (such as the Mini Mental State Examination (MMSE; Folstein et al, 1975) and the abbreviated mental test (AMT; Hodkinson, 1972)), or whether clinical judgement was relied upon.

Data analysis. Responses were analysed in frequencies and percentages for categorical data and were reported by themes. Fisher's exact test and $\chi^{2}$-test, with odds ratios and confidence intervals, were used to compare the differences between responses of late trainees (defined as year 4-5) and early trainees (defined as year 1-3). SPSS version 19 statistical software package (SPSS, Inc., Chicago, IL, USA) was used for data analysis.

\section{RESULTS}

The response rate was $93 \%(n=64$ out of 69$)$. The mean age of respondents was $32.3 \pm 3.1$ years (range $27-42$ years) and $64.1 \%$ $(n=41)$ were female. Trainees in year $1-3$ represented $67.2 \%$ of 
the sample; $32.8 \%$ were in year $4-5$. There was $7 \%$ missing data in the questionnaire responses.

Geriatrics training before oncology specialty training. Less than 6 months undergraduate and postgraduate geriatrics training was received by $85.7 \%$ and $43.5 \%$ of respondents, respectively (Figure 1).

Geriatric oncology training during specialist training. A total of $66.1 \%(N=41)$ of the respondents reported never having received any training on the particular needs of older people with cancer during their specialty training. A further $19.4 \%(N=12)$ reported to have received this training only once (Figure 2). Even with latestage trainees (year $4-5)$ alone, $52.4 \%(N=11)$ had never received training and a further $38.1 \%(N=8)$ had received training only once.

Geriatric-specific issues common in oncology patients (e.g. delirium and falls). Of those who had received training, the majority received it $\geqslant 3$ years ago (Table 1 ). Late trainees were less likely to have training in delirium, MCA, falls and polypharmacy than early trainees (Table 2). Respondents reported wanting training in a variety of topics, most commonly around cognitive impairment/delirium $(n=18)$, polypharmacy $(n=17)$, cardiac $(n=9)$ and comorbidity management $(n=7)$, as well as discharge planning $(n=7)$.

\section{Current oncology practice in patients with cognitive impairment}

Cognitive assessments. Cognition was rarely/never assessed by $45.9 \%$ of the respondents. Of those who did assess cognition, AMT (59.7\%) was the most commonly used method, followed by clinical judgement (48.4\%) and then MMSE (40.6\%). Respondents could answer with multiple responses.

Seeking senior input and follow-up. Of the respondents, $94.6 \%$ would always/often discuss cognitively impaired patients with a senior and $68.5 \%$ would always/often highlight cognitive impairment to the GP. Following a referral for further cognitive tests, $50 \%$ would rarely/never see a patient again to reconsider cancer treatment afterwards.

Consent and mental capacity assessment. In patients with cognitive impairment, $27.3 \%$ of respondents would never consent such a patient and a further $50.9 \%$ would rarely do so. The MCA was never/rarely used to decide about the patient understanding in $38.9 \%$.

Confidence in clinical practice. When considering cancer treatment recommendations, fewer trainees felt confident assessing risk ( $v s$ benefit) in older patients $(70+$ years) than in younger patients (patient in their $40 \mathrm{~s}$ in the vignette). Of the respondents, $81.4 \%$ were confident/extremely confident assessing risk in younger

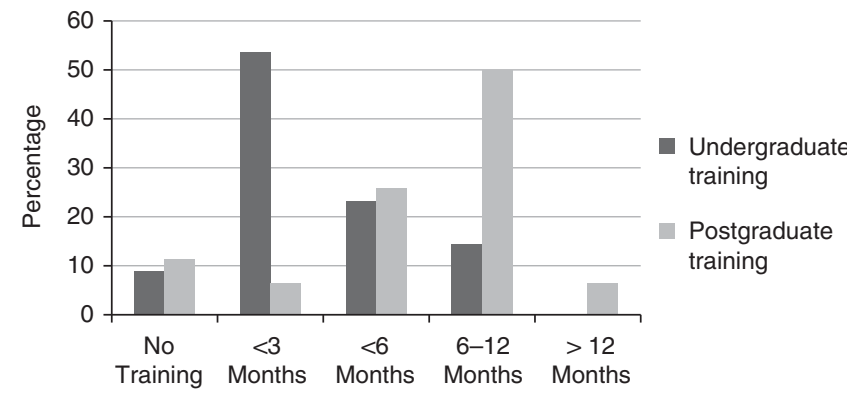

Figure 1. Geriatrics training. Geriatrics training before specialty training. patients compared with $27.1 \%$ in assessing older patients. This dropped to $10.2 \%$ for older patients with dementia. Only $25.4 \%$ felt confident/extremely confident in managing multiple comorbidities in older patients with cancer. Although late trainees were more confident than early trainees, their confidence was still lower for older $(40.0 \%)$ vs younger $(85.0 \%)$ patients, and was also lower still in patients with dementia (25.0\%).

Practice and attitudes. Of the respondents, 50.8\% reported it true/mostly true that on some occasions it is justifiable to make a cancer treatment decision based on a patient's chronological age. Further, $40.7 \%$ of the respondents believed it mostly false/false that patients $70+$ can often tolerate similar treatment regimens to younger patients and $83.1 \%$ believed it true/ mostly true that patients $70+$ received less active and less intensive treatment than that received by younger patients.

Perceived barriers to treatment in older people. Lack of evidence always/often being a barrier was described by $54.1 \%$ of the respondents, although $41.0 \%$ reported that lack of efficacy was rarely/never a barrier (Table 3). Oncologists always/often felt uncomfortable/uncertain was reported by $23.7 \%$ of respondents.

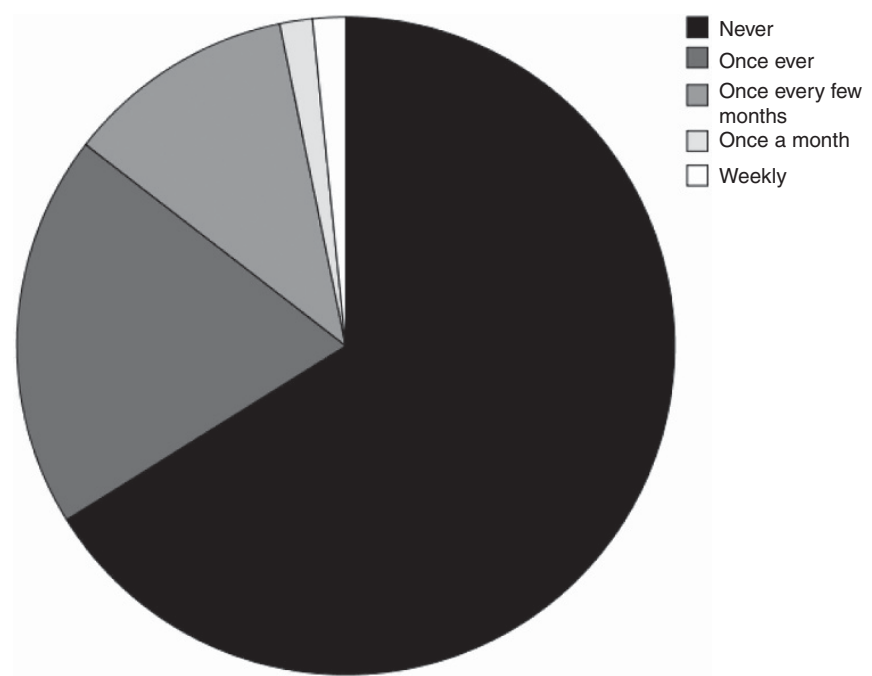

Figure 2. Specialty training. Specialty training on the needs of older people with cancer.

Table 1. Last training in geriatrics-specific issues

\begin{tabular}{|l|c|c|c|}
\hline & Never (\%) & $\begin{array}{c}\geqslant \text { Years ago } \\
\text { (\%) }\end{array}$ & $\begin{array}{c}\leqslant \text { Years ago } \\
\text { (\%) }\end{array}$ \\
\hline Nutrition & 24.2 & 38.7 & 37.1 \\
\hline Delirium & 14.5 & 58.1 & 27.4 \\
\hline MCA & 11.3 & 43.5 & 45.2 \\
\hline Polypharmacy & 14.5 & 53.2 & 32.3 \\
\hline Falls & 6.4 & 52.5 & 31.1 \\
\hline Continence & 27.4 & 53.2 & 19.4 \\
\hline \multicolumn{4}{|l|}{ Abbreviation: MCA= Mental Capacity Act. } \\
\hline
\end{tabular}




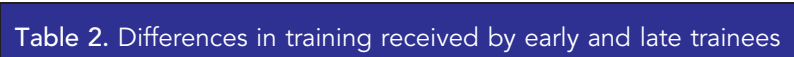

\begin{tabular}{|c|c|c|c|c|}
\hline & Late trainees & Early trainees & OR $(95 \% \mathrm{Cl})$ & $P$-value \\
\hline No delirium training & $28.6 \%(n=6 / 21)$ & $7.3 \%(n=3 / 41)$ & $5.07(1.12-22.9)$ & 0.05 \\
\hline No MCA training & $23.8(n=5 / 21)$ & $4.9 \%(n=2 / 41)$ & $8.86(1.51-52.10)$ & 0.04 \\
\hline No falls training & $35.0 \%(n=7 / 20)$ & $7.3 \%(n=3 / 41)$ & $6.82(1.53-30.32$ & 0.01 \\
\hline No polypharmacy training & $28.6(n=6 / 21)$ & $7.3 \%(n=3 / 41)$ & $5.07(1.12-22.92)$ & 0.05 \\
\hline No continence training & $38.1 \%(n=8 / 21)$ & $22.0 \%(n=9 / 41)$ & $2.19(0.69-6.91)$ & 0.18 \\
\hline No nutrition training & $33.3 \%(n=7 / 21)$ & $19.5 \%(8 / 41)$ & $2.06(0.63-6.79)$ & 0.23 \\
\hline
\end{tabular}

\begin{tabular}{|c|c|c|c|}
\hline $\begin{array}{l}\text { Barriers to } \\
\text { chemotherapy }\end{array}$ & $\begin{array}{l}\text { Always/ } \\
\text { often (\%) }\end{array}$ & $\begin{array}{c}\text { Sometimes } \\
(\%)\end{array}$ & $\begin{array}{c}\text { Rarely/ } \\
\text { never (\%) }\end{array}$ \\
\hline Lack of evidence & 54.1 & 29.5 & 16.4 \\
\hline $\begin{array}{l}\text { Older people can't tolerate } \\
\text { chemotherapy }\end{array}$ & 26.2 & 62.3 & 11.4 \\
\hline Lack of efficacy & 13.1 & 45.9 & 41.0 \\
\hline $\begin{array}{l}\text { Older people don't want } \\
\text { chemotherapy }\end{array}$ & 21.3 & 68.9 & 9.8 \\
\hline $\begin{array}{l}\text { Oncologists feel } \\
\text { uncomfortable/uncertain }\end{array}$ & 23.7 & 55.9 & 20.3 \\
\hline
\end{tabular}

\section{DISCUSSION}

Principle findings. This survey of UK medical oncology trainees highlights several deficiencies in UK oncology training with respect to older people with cancer. Two thirds of the trainees had not received any training in the particular needs of older people with cancer during their specialty training. Late trainees were less likely to have received training in conditions, such as delirium, than early trainees. We would postulate that this may reflect changes in core medical training where the curriculum does now includes competencies in conditions such as delirium and falls. It may also reflect the development of national guidelines, for example, the NICE guidance on delirium published in 2010 (NICE CG103).

Confidence in risk assessing older people was lacking. Training and practice around cognitive impairment was particularly low. Many never/rarely used the MCA to decide about capacity to consent to treatment. Trainees most commonly used AMT (Hodkinson, 1972), followed by clinical judgement to assess cognition. AMT is less sensitive and specific than the MMSE (MacKenzie et al, 1996). Even with MMSE, although validated and the most commonly used cognitive screen, it has significant limitations (Ismail et al, 2010). It lacks assessment for frontal and executive function. It has known limitations in the context of high pre-morbid intelligence and can overdiagnose in those with more limited education. The accuracy of clinical judgment in recognising dementia and cognitive impairment has not been studied with oncologists, although a meta-analysis of general practioners demonstrated difficulty in identifying mild cognitive impairment or mild dementia (Mitchell et al, 2011). Issues around identifying cognitive impairment and assessing mental capacity is clearly not unique to oncology. A retrospective study of neurosurgeons consenting and treating intracranial tumours similarly showed that few assessed cognition (Kerrigan et al, 2012). They also found that few patients were deemed without capacity to consent. Taking into account that intracranial tumours affect cognition and, by that token, may impact on capacity, this was suprisingly low.

Confidence was particularly lacking for assessing risk in patients with dementia, regardless of stage of training. With an ageing population and increasing numbers of patients with a spectrum of cognitive deficits, being able to make this balanced judgement will become increasingly important.

Strengths and limitations. The survey highlights a key area of concern and gives early indications of where the gaps may lie in UK oncology training. The response rate was high, strengthening the validity of this group as a representative sample. This was likely incentivised by a planned geriatric oncology lecture to be based on the respondents identified needs. There was only $7 \%$ missing data and the content validity ratio was high (0.80), suggesting the content was appropriate and easily understood.

The study has limitations. There may be recall or responder bias. In our study, we obtained 64 responses from a population size of 221 medical oncology trainees. This provided us with a reasonably small margin of error (10.4\%) at 95\% confidence level. A sample size of 141 would be required to achieve a 5\% margin of error. Our suboptimal sample size may contribute to some nonsignificant results.

The survey targeted medical oncology trainees. We cannot exclude that the training needs of clinical oncology trainees may be different. However, it is unlikely in light of the similarities with neither curriculum having specific geriatric oncology learning objectives, and the population treated being the same.

In the context of the existing literature. This survey, to the authors' knowledge, is the first in the United Kingdom identifying gaps in training around the specific needs of older people with cancer. There has been very little research worldwide into geriatric oncology training needs. The existing research (mainly US-based) has concentrated on identifying training needs from the perspective of the trainer (Cohen, 1997; Kennedy, 1997). This survey is the first to explore the needs as perceived by the trainees themselves.

We identified deficiencies in training, clinical practice and confidence, which are unlikely to be unique to the United Kingdom. Many western countries have equally made little progress in evolving training to reflect the ageing population and the challenges this brings. Even in countries such as the United States, where the curriculum does include specific learning objectives (Muss et al, 2005), we found no evidence in the literature demonstrating that the addition of these learning objectives translated into increased confidence, competence or better outcomes for older people.

Future research. Future research is required in the United Kingdom and also worldwide. Curricula need to evolve and the impact evaluated. This should be evaluated not only from the 
perspective of improving the provision of training, but increasing competence, confidence and, most importantly, improving patient outcomes.

Research must consider the perceived needs from the perspective of the trainee, trainer, patients, health care organisations and policy makers. How to deliver this training should also be explored, especially as there are no geriatric oncology specialist centres in the United Kingdom. Similar evaluations should be considered in other countries, as the needs of trainees in other countries may differ with different populations and different training structures.

Implications. The survey deserves careful consideration and further evaluation by the UK training bodies. Urgent changes to curricula should be considered. Training objectives will need to consider the variability of trainees' previous experiences as demonstrated in this survey. Competencies should be achievable and standardised to ensure all trainees reach a minimum competency in common conditions relevant to all specialties.

This survey also highlights the need for collaborative working with specialists, such as geriatricians, to complement each others' skills. Geriatrician liaison models are becoming increasingly utilised by other specialties, such as orthopaedics (Gilchrist et al, 1988) and surgery (Harari et al, 2007). This is reflected in the geriatrics curriculum with expected competencies in topics such as orthogeriatrics. To develop such liaison models in cancer, it may equally be important to improve cancer learning in the geriatrics curriculum.

Of course, changes in postgraduate medical education alone will not improve care for older people without other strategies. The training of oncology nurses and allied health care professionals should develop in parallel. Further research is needed into optimising outcomes in frail and multimorbid patients. Decisionmaking before and after specific interventions should be evaluated with appropriate outcome measures, such as quality of life and/or prolonged survival. Moreover, health care policy makers need to consider how services should be configured to best meet these patients needs.

There is an urgent need for change, to equip the oncologists of the future with adequate skills to be able to confidently manage the complexities of this patient group. The need for change requires recognition not only by educational bodies, but by leaders of health care policy in the United Kingdom. Only then can we start to make headway in the challenge of improving the care of older people with cancer.

\section{ACKNOWLEDGEMENTS}

We thank the Macmillan Cancer Support for their help with disseminating the survey via Survey Monkey, and the Joint Royal College of Physicians Training Board (JRCPTB) for providing the current number of medical oncology trainees, 11.6.12. TK and DH are supported by grants from the Macmillan Cancer Support and the UK Department of Health, and from Guys and St Thomas' Charity. YW is supported by the National Institute for Health Research (NIHR) Biomedical Research Centre at Guy's \& St Thomas' NHS Foundation Trust and Kings College London.

\section{REFERENCES}

Allan-Gibbs R (2010) Falls and hospitalized patients with cancer: a review of the literature. Clin J Oncol Nurs 14(6): 784-792.

Bates TS, Wright MP, Gillatt DA (1998) Prevalence and impact of incontinence and impotence following total prostatectomy assessed anonymously by the ICS-male questionnaire. Eur Urol 33(2): 165-169.

Bennett JM, Hall WJ, Sahasrabudhe DM, Balducci L (2010) Enhancing geriatric oncology training to care for elders: A clinical initiative with long term follow-up. J Geriatr Oncol 1(1): 4-12.

Bennett JM, Sahasrabudhe DM, Hall WJ (1997) Medical oncology and geriatric medicine: is it time for fellowship integration? Cancer 80(7): 1351-1353.

Cohen HJ (1997) The oncology geriatric education retreat. Cancer 80(7): 1354-1356.

Coleman MP, Forman D, Bryant H, Butler J, Rachet B, Maringe C, Nur U, Tracey E, Coory M, Hatcher J, McGahan CE, Turner D, Marrett L, Gjerstorff ML, Johannesen TB, Adolfsson J, Lambe M, Lawrence G, Meechan D, Morris EJ, Middleton R, Steward J, Richards MA. ICBP Module 1 Working Group (2011) Cancer survival in Australia, Canada, Denmark, Norway, Sweden, and the UK, 1995-2007 (the International Cancer Benchmarking Partnership): an analysis of population-based cancer registry data. Lancet 377(9760): 127-138.

Extermann M (2005) Older patients, cognitive impairment, and cancer: an increasingly frequent triad. J Natl Compr Canc Netw 3(4): 593-596.

Ferri CP, Prince M, Brayne C, Brodaty H, Fratiglioni L, Ganguli M, Hall K, Hasegawa K, Hendrie H, Huang Y, Jorm A, Mathers C, Menezes PR, Rimmer E, Scazufca M. Alzheimer's Disease International (2005) Global prevalence of dementia: a Delphi consensus study. Lancet 366(9503): 2112-2117.

Folstein MF, Folstein SE, McHugh PR (1975) 'Mini-mental state'. A practical method for grading the cognitive state of patients for the clinician J Psychiatr Res 12(3): 189-198.

Gilchrist WJ, Newman RJ, Hamblen DL, Williams BO (1988) Prospective randomised study of an orthopaedic geriatric inpatient service. BMJ 297: $1116-111$.

Gupta SK, Lamont EB (2004) Patterns of presentation, diagnosis, and treatment in older patients with colon cancer and comorbid dementia J Am Geriatr Soc 52(10): 1681-1687.

Harari D, Hopper A, Dhesi J, Babic-Illman G, Lockwood L, Martin F (2007) Proactive care of older people undergoing surgery ('POPS'): designing, embedding, evaluating and funding a comprehensive geriatric assessment service for older elective surgical patients. Age Ageing 30(2): 190-196.

Hodkinson HM (1972) Evaluation of a mental test score for assessment of mental impairment in the elderly. Age Ageing 1(4): 233-238.

Ismail Z, Rajji TK, Shulman KI (2010) Brief cognitive screening instruments: an update. Int J Geriatr Psychiatry 25(2): 111-120.

Kennedy BJ (1997) Aging and cancer. Cancer 80(7): 1270-1272.

Kerrigan S, Dengu F, Erridge S, Grant R, Whittle IR (2012) Recognition of mental incapacity when consenting patients with intracranial tumours for surgery: how well are we doing? Br J Neurosurg 26(1): 28-31.

Khattak MA (2011) Training opportunities in geriatric oncology. Asia Pac J Clin Oncol 7(4): 401-402.

Lawlor PG, Gagnon B, Mancini IL, Pereira JL, Hanson J, Suarez-Almazor ME, Bruera ED (2000) Occurrence, causes, and outcome of delirium in patients with advanced cancer: a prospective study. Arch Intern Med 160(6): 786-794.

Lawshe CH (1975) A quantitative approach to content validity. Personnel Psychol 28: 563-575.

Lichtman SM (2000) Integration of geriatrics in oncology training - the relationship between the academic center and the community. Crit Rev Oncol Hematol 33(1): 57-59.

MacKenzie DM, Copp P, Shaw RJ, Goodwin GM (1996) Brief cognitive screening of the elderly: a comparison of the Mini-Mental State Examination (MMSE), Abbreviated Mental Test (AMT) and Mental Status Questionnaire (MSQ). Psychol Med 26(2): 427-430.

Mitchell AJ, Meader N, Pentzek M (2011) Clinical recognition of dementia and cognitive impairment in primary care: a meta-analysis of physician accuracy. Acta Psychiatr Scand 124(3): 165-183.

Muss HB, Von Roenn J, Damon LE, Deangelis LM, Flaherty LE, Harari PM, Kelly K, Kosty MP, Loscalzo MJ, Mennel R, Mitchell BS, Mortimer JE, Muggia F, Perez EA, Pisters PWT, Saltz L, Schapira L, Sparano J (2005) ACCO:ASCO Core Curriculum Outline. J Clin Oncol 23(9): 2049-2077.

Naeim A, Hurria A, Rao A, Cohen H, Heflin M, Seo P (2010) The need for an aging and cancer curriculum for hematology/oncology trainees. J Geriatr Oncol 1(2): 109-113. 
Nicholson TR, Cutter W, Hotopf M (2008) Assessing mental capacity: the Mental Capacity Act. BMJ 336(7639): 322-325.

Stuck AE, Siu AL, Wieland GD, Adams J, Rubenstein LZ (1993)

Comprehensive geriatric assessment: a meta-analysis of controlled trials. Lancet 342(8878): 1032-1036.

Terret C, Zulian G, Droz JP (2004) Statements on the interdependence between the oncologist and the geriatrician in geriatric oncology. Crit Rev Oncol Hematol 52(2): 127-133.
Tofthagen C, Overcash J, Kip K (2012) Falls in persons with chemotherapyinduced peripheral neuropathy. Support Care Cancer 20(3): 583-589.

This work is published under the standard license to publish agreement. After 12 months the work will become freely available and the license terms will switch to a Creative Commons AttributionNonCommercial-Share Alike 3.0 Unported License.

Supplementary Information accompanies this paper on British Journal of Cancer website (http://www.nature.com/bjc) 